\title{
Tau Protein is Associated with Longitudinal Memory Decline in Cognitively Healthy Subjects with Normal Alzheimer's Disease Cerebrospinal Fluid Biomarker Levels
}

\author{
Adrià Tort-Merino ${ }^{\mathrm{a}}$, Jaume Olives ${ }^{\mathrm{a}}$, María León ${ }^{\mathrm{a}}$, Claudia Peñaloza $^{\mathrm{b}}$, Natalia Valech ${ }^{\mathrm{a}}$, \\ Miguel A. Santos-Santos ${ }^{\mathrm{b}}$, Estela Càmara ${ }^{\mathrm{b}}$, Petra Grönholm-Nyman ${ }^{\mathrm{c}}$, Pablo Martínez-Lage ${ }^{\mathrm{d}}$, \\ Juan Fortea ${ }^{\mathrm{e}, \mathrm{f}}$, José L. Molinuevo ${ }^{\mathrm{a}, \mathrm{g}}$, Raquel Sánchez-Valle ${ }^{\mathrm{a}, \mathrm{h}}$, Matti Laine ${ }^{\mathrm{c}}$, \\ Antoni Rodríguez-Fornells ${ }^{\mathrm{b}, \mathrm{i}, \mathrm{j}}$ and Lorena Rami ${ }^{\mathrm{a}, \mathrm{h}, *}$ \\ aAlzheimer's Disease and Other Cognitive Disorders Unit, Neurology Service, Hospital Clínic, Barcelona, Spain \\ ${ }^{\mathrm{b}}$ Cognition and Brain Plasticity Group, Bellvitge Biomedical Research Institute- IDIBELL, L'Hospitalet de \\ Llobregat, Barcelona, Spain \\ ${ }^{\mathrm{c}}$ Department of Psychology, Åbo Akademi University, Turku, Finland \\ ${ }^{\mathrm{d} N e u r o l o g i ́ a, ~ F u n d a c i o ́ n ~ C I T A-A l z h e ́ i m e r ~ F u n d a z i o a, ~ C e n t r o ~ d e ~ I n v e s t i g a c i o ́ n ~ y ~ T e r a p i a s ~ A v a n z a d a s, ~}$ \\ San Sebastián, Guipúzcoa, España \\ ${ }^{\mathrm{e}}$ Memory Unit, Department of Neurology, Hospital de la Santa Creu i Sant Pau and Institute of Biomedical \\ Research, Barcelona, Spain \\ ${ }^{\mathrm{f}}$ Centro de Investigación Biomédica en Red de Enfermedades Neurodegenerativas, CIBERNED, Madrid, Spain \\ ${ }^{\mathrm{g}}$ Barcelonaßeta Brain Research Center, Pasqual Maragall Foundation, Barcelona, Spain \\ ${ }^{\mathrm{h}}$ August Pi i Sunyer Biomedical Research Institute (IDIBAPS), Barcelona, Spain \\ ${ }^{\mathrm{i}}$ Catalan Institution for Research and Advanced Studies (ICREA), Barcelona, Spain \\ ${ }^{\mathrm{j} D e p a r t m e n t}$ of Cognition, Development and Education Psychology, University of Barcelona, L'Hospitalet de \\ Llobregat, Spain
}

Handling Associate Editor: Montse Alegret

Accepted 29 April 2019

\begin{abstract}
. memory decline.

\footnotetext{
*Correspondence to: Lorena Rami, PhD, Alzheimer's Disease and Other Cognitive Disorders Unit, Neurology Service, Hospital Clínic, IDIBAPS. Villarroel 170. 08036. Barcelona. Spain. Tel.: +34 932275785; Fax: +34 932275783; E-mail: 1rami@ clinic.cat.
}

Background: We investigated a sample of cognitively healthy subjects with normal Alzheimer's disease (AD) cerebrospinal fluid (CSF) biomarker levels to identify the earliest variables related to longitudinal memory changes.

Objective: Employing a new highly demanding learning and memory test (the Ancient Farming Equipment Test; AFE-T), we aimed to investigate whether a biomarker related to neurodegeneration (i.e., CSF tau) was associated with longitudinal 
Methods: Thirty-two cognitively and biologically normal (CBN) subjects underwent MRI, neuropsychological assessment, and the AFE-T at baseline and 18 months later. To explore the relationship between cognitive performance and relevant factors, a linear model was set up. For a secondary analysis that further explore the effect of tau, the subjects were divided into CBN-Tau ${ }^{\downarrow}(\mathrm{tau}<228.64 \mathrm{pg} / \mathrm{ml} ; n=16)$ and $\mathrm{CBN}^{-\mathrm{Tau}^{\uparrow}}{ }^{\uparrow}\left(\mathrm{tau}^{>} 228.64 \mathrm{pg} / \mathrm{ml} ; n=16\right)$. We also performed voxel-based morphometry (VBM) to identify regions of grey matter volume that would predict both baseline and longitudinal cognitive performance.

Results: Our main finding was an association between CSF tau and longitudinal memory decline measured with AFE-T $(B=-0.17, p<0.05 ; r=-0.414 ; p<0.01)$, and further analyses showed different evolvement between subgroups, with an accelerated decline in individuals with higher tau $(\mathrm{F}(1,31)=8.37 ; p<0.01)$. VBM results suggested that AFE-T performance is related to grey matter volume in a medial temporal, middle frontal, and posterior cerebellar network at baseline, and that there are strategic brain areas driving the longitudinal cognitive changes.

Conclusions: The present findings provide evidence for structural and biological markers linked to cognitive aging by highlighting the role of tau, a marker of neurodegeneration, which can be related with the earliest memory changes in healthy subjects.

Keywords: Aging, biomarkers, cognition, early detection, memory decline, tau, voxel-based morphometry

\section{INTRODUCTION}

Understanding the factors underlying age-related changes in cognition has long been a challenge. Since cognitive changes in normal aging and in incipient pathological processes (e.g., preclinical Alzheimer's disease; AD) are closely related, there is a need to identify the earliest factors driving the cognitive decline in both populations in order to ensure an early detection of the pathological processes. While there is extensive literature on the aging process in large cohorts of cognitively impaired and unimpaired subjects, we have very little information on biomarkers of age-related cognitive changes in cognitively healthy subjects with a confirmed normal AD cerebrospinal fluid (CSF) biomarker profile.

The cognitive profile in normal aging has been well-documented in the scientific literature [1-3]. However, one important question that remains open concerns the factors related to these observed cognitive changes. First, demographic variables such as age, years of education, and cognitive reserve [4-6] are known to have an impact on the trajectory of cognition over the life span. A prospective study involving a large sample of 2,509 cognitively healthy elderly adults reported that both age and educational level predicted maintenance of cognitive function over an 8-year period [7]. Second, some neuropsychological variables have been identified as predictors of cognitive decline. Memory decline has been considered as the major cognitive risk factor for developing age-related pathologies, such as mild cognitive impairment (MCI) or AD [8]. Third, the maintenance of cognitive functioning in aging is thought to be primarily related to brain maintenance, that is, relative lack of structural and functional brain changes [9]. In line with this, a recent report suggested that subjects with larger medial temporal lobe (MTL) volumes at baseline were more likely to maintain their cognitive function over time [10]. Fourth, biological markers on cognition have been a topic of intensive research during the last few years. The most studied AD CSF biomarkers are the tau protein levels and the 42 amino acid form of amyloid- $\beta$ $\left(A \beta_{42}\right)$. Some studies have suggested that CSF tau levels rather than $A \beta$ pathology are more closely related to cognition, specifically to memory decline [11-13].

Due to the proximity of cognitive changes related to normal aging versus incipient pathological processes, there is an increasing need to develop more sensitive tests for an early detection of subtle cognitive difficulties in populations at risk. For that reason, new highly demanding neuropsychological tests such as the Face Name Associative Memory Exam [14-16] or the Short-Term Memory Binding test [17] have been developed. Using previous research on the neural mechanisms involved in language learning and memory, we recently evaluated a highly demanding learning and memory test called the Ancient Farming Equipment Test (AFE-T) (for a review, see Laine \& Salmelin [18]). This task engages the declarative memory system in learning to associate unfamiliar names (new labels or words) to completely new objects. To date, the AFE paradigm has been used to study acquisition of new words in groups of healthy adults $[19,20]$ and, in two studies, in MCI and AD patients [21, 22]. A fMRI study using the AFE paradigm in an aphasic patient and in healthy controls showed a clear involvement 
of MTL regions during the learning phase [23]. In our recent study, we employed the AFE-T to detect subtle cognitive difficulties in preclinical AD subjects. The AFE-T was found to be a promising tool for characterizing the cognitive profile of preclinical $\mathrm{AD}$, being sensitive enough to detect initial learning difficulties in our at-risk population. Furthermore, the AFE-T was associated with the CSF $A \beta_{42} /$ tau ratio [24].

Since there is recent literature regarding the relationships between cognitive function and AD CSF biomarkers in cognitively normal subjects [25-29], the present research pushed further by focusing on a specific sample of cognitively healthy subjects with normal AD CSF biomarker levels. The aim of the present study was to examine and follow up this well-characterized sample in order to detect demographical, structural and biological variables related to the earliest cognitive changes in aging. Employing the sensitive AFE-T cognitive measure, we specifically wanted to investigate whether a biomarker related to neurodegeneration (i.e., CSF tau) is associated with the earliest longitudinal decline of learning and memory in cognitively and biologically normal aging.

\section{MATERIAL AND METHODS}

\section{Participants}

The present participants represent a sub-sample of Tort-Merino et al. [24], and thus the present methods description follows that paper. Thirty-two cognitively healthy subjects with normal AD CSF biomarker levels were included in the present study and followed up for 18 months. The participants were recruited at three Spanish memory centers: Hospital Clinic (HC) and Hospital de la Santa Creu i Sant Pau (HSP) in Barcelona, as well as the CITA-Alzheimer Foundation (CITA) in San Sebastian. Due to the nature of this recruitment, some of the subjects included in the study presented memory complaints. The ethics committee of the Hospital Clinic of Barcelona approved the study, and all participants provided a signed, informed consent before undergoing the neuropsychological assessment, MRI and the lumbar puncture. All subjects had to meet the following inclusion criteria: a) at least three years of formal education, b) Mini-Mental State Examination (MMSE) score >24, and c) Clinical Dementia Rating (CDR) score $=0$ and objective cognitive performance within the normal range (cutoff $1.5 \mathrm{SD}$ from normative mean) in all tests on a neuropsychological battery (see below). The following exclusion criteria were applied: a) presence of any neurological diagnosis, $b$ ) presence of a serious or unstable medical condition, c) diagnosis of a major psychiatric disorder including schizophrenia, major depression or substance abuse, and d) presence of any abnormality in CSF A $\beta_{42}$, tau, and/or phosphorylated tau at threonine-181 (ptau) levels.

For a secondary analysis that further explored the effect of CSF tau in normal aging, we divided the present sample into CBN-Tau ${ }^{\downarrow}$ and $\mathrm{CBN}-\mathrm{Tau}^{\uparrow}$ subgroups according to their CSF tau levels. These secondary analyses were done in order to visualize the main findings of the study. The mean of the CSF tau values $(228.64 \mathrm{pg} / \mathrm{ml})$ of the 32 subjects was used as a cut-off point to ensure an equal distribution between groups. Subjects with CSF tau levels below $228.64 \mathrm{pg} / \mathrm{ml}$ were classified as CBN-Tau ${ }^{\downarrow}(n=16)$ and subjects with CSF tau above $228.64 \mathrm{pg} / \mathrm{ml}$ were included in the $\mathrm{CBN}-\mathrm{Tau}^{\uparrow}$ group $(n=16)$.

\section{Determination of biological and AD CSF biomarkers}

All subjects underwent a lumbar puncture between 9 a.m. and 12 p.m. to collect $10 \mathrm{ml}$ of CSF. The samples were centrifuged and stored in polypropylene tubes at $-80^{\circ} \mathrm{C}$ within the first hour after extraction. CSF $A \beta_{42}$ levels, tau, and ptau were measured by enzyme-linked immunosorbent assay kits (Innogenetics, Ghent, Belgium). Cut-off values of abnormality for each AD CSF biomarker were defined according to previous work [30]: a) $\mathrm{A} \beta_{42}$ $\leq 550 \mathrm{pg} / \mathrm{ml}, \mathrm{b}$ ) tau $\geq 400 \mathrm{pg} / \mathrm{ml}$ for subjects between 50-70 years old, and $\geq 450 \mathrm{pg} / \mathrm{ml}$ for subjects older than 70 years, and c) ptau $\geq 75 \mathrm{pg} / \mathrm{ml}$. As noted in the inclusion criteria, all subjects included in the study presented normal levels for all AD biomarkers. The AFE-T administrator and the participants were blind to CSF results.

\section{Apolipoprotein E analysis}

Genomic DNA was extracted from peripheral blood of probands using the QIAamp DNAblood minikit (Qiagen AG, Basel, Switzerland). APOE genotyping was performed by polymerase chain reaction amplification and HhaI restriction enzyme digestion. Both the AFE-T administrator and the study participants were blind to the $A P O E$ results. 


\section{Neuropsychological assessment}

All participants were assessed both at the baseline and at the follow-up session with a comprehensive neuropsychological battery, administered by a trained neuropsychologist blind to the CSF results. The battery encompassed four cognitive domains. The memory domain included the Free and Cued Selective Reminding Test (FCSRT) [31], the language domain comprised of the Boston Naming Test [32], and a Semantic Fluency Task [33]; the visual perception domain contained the Number Location subtest of the VOSP battery [34]; and the executive functions domain consisted of the Trail Making Test [35], the Stroop Test [36], the Symbol Digit Modalities Test [37], and the Digit Span test of the WAIS [38]. Global cognition was assessed with the MMSE [39]. Premorbid intelligence was assessed with the Spanish Word Accentuation Test [40]. Subjective memory complaints were measured by the Subjective Cognitive Decline Questionnaire (SCD-Q) [41]. The average time lapse between the baseline neuropsychological assessment and the baseline AFE-T (list A) was +0.4 (SD 0.6) months and the time lapse between the follow-up neuropsychological assessment and the follow-up AFE-T (list B) was -0.4 (SD $0.4)$ months.

\section{The Ancient Farming Equipment Test}

The AFE-T called for learning of two lists of new object/name pairs. For both lists, the objects were 24 black-and-white images of ancient farming equipment taken from the AFE paradigm [18]. Each object was paired with a pseudoword, that is, a non-existing word that follows the phonotactic rules of Spanish [42]. The object names consisted of 14 bisyllabic and 10 trisyllabic pseudowords that do not exist in the Spanish dictionary. All stimuli were presented on a computer screen against a white background using the E-prime 2.0 version (Psychology Software Tools, Inc., PA, USA).

The study had a total duration of 18 months and included a baseline testing session and an 18-month follow-up. List A was administered at the baseline assessment and list B at the 18-month follow-up. The assessments are explained in detail below.

\section{Initial learning sessions, total learning score, and immediate cued recall}

List A was administered in two initial learning sessions that were performed on two consecutive days.
Each learning session included a total of seven runs and took approximately $45 \mathrm{~min}$. Before starting the learning phase, each of the 24 object/name pairs was displayed for seven seconds with a $500 \mathrm{~ms}$ pause between the pairs. The participants were asked to read aloud the name of the object printed below, and to try to learn each object/name pair. After the presentation, the seven learning runs were performed. In each run, the participants were presented with the objects one at a time, and were asked to spontaneously say its name aloud. They were given a maximum of $7 \mathrm{~s}$ to recall the name of each object. After this, the correct name appeared below the object for $4 \mathrm{~s}$, regardless of whether the participant had been able to produce the correct name. The following object was presented after $500 \mathrm{~ms}$. The order of presentation in each run was randomized. For each run, the range of scores was $0-24$.

After the last run of the second learning day (i.e., total learning score), the immediate cued recall (ICR) was administered. In this test, each object was presented one at a time. When the object appeared, the experimenter verbally provided the first syllable of the object's name (phonemic cue). The participant then had a maximum of $7 \mathrm{~s}$ to provide the correct name. This time feedback (i.e., the correct name) was not provided after the response.

\section{Follow-up session at 18 months}

The 18-month follow-up included exactly the same procedure as at the baseline except that list B was administered.

\section{Scoring system}

All verbal responses were recorded for offline scoring. Following the scoring procedure of the AFE paradigm, a response was considered correct (score $=1$ ) when (a) the participant recalled the exact name of the object, or when (b) the name recalled differed only by a single phoneme from the original name. Under (b), the following cases were considered: substitution, addition, or omission of a single phoneme at any given position of the word, or a change in position of an otherwise correct phoneme. This criterion was applied for all runs.

\section{Validation study}

A validation study with 30 young adults was conducted to confirm that the word lists A and B had comparable difficulty. We ran independent $t$-tests to explore possible between-group differences between word lists A and B. In addition, we compared the per- 
formances between the participants of the validation study (younger adults) and the subjects included in the study.

\section{Neuroimaging}

\section{Acquisition}

For each participant, two T1-weighted, highresolution, MPRAGE structural MRI (echo time [TE] $2.98 \mathrm{~ms}$, repetition time [TR] $2300 \mathrm{~ms}$, inversion time $900 \mathrm{~ms}$, flip angle $9^{\circ}$, bandwidth $240 \mathrm{~Hz} /$ pixel, matrix $256 \times 256,240$ axial slices, isometric voxel size 1/4 $1.0 \mathrm{~mm}^{3}$ ) scans were acquired at the IDIBAPS's Imaging core facilities with a 3T whole-body MRI scanner (Siemens Magnetom Trio; Hospital Clínic, Barcelona).

The mean time between scans was 1.9 (SD 0.2) years. Three participants were excluded due to severe motion artifacts.

\section{Processing and analyses}

Image processing was performed using the unified segmentation procedure [43], DARTEL toolbox [44], and Pairwise Longitudinal Registration [28] toolbox implemented in SPM12 (Welcome Trust for Neuroimaging) according to standard procedures. In the whole sample, we performed whole brain voxel-based morphometry (VBM) analyses evaluating which regions of grey matter volume significantly predicted the total learning score and the immediate cued recall of the AFE-T at baseline (cross-sectional VBM, $n=29$ ), as well as their longitudinal change (longitudinal VBM), using multiple regression within the SPM12 environment controlling for age and total intracranial volume.

In the longitudinal VBM analysis, we only included subjects whose scores declined $(n=20$ for total learning score; $n=23$ for immediate cued recall), because our focus was on identifying the brain regions associated with impairment over time. We chose these two measures as they are most representative of total learning and cued recall, respectively. We reported results at a threshold of $p<0.001$ uncorrected for multiple comparisons and used a threshold of $p<0.005$ uncorrected for multiple comparisons for visualization purposes (http://www.nitrc.org/projects/mricron).

\section{Statistical analyses}

Statistical analyses were performed using the SPSS (v. 22.0) package for Windows. Following the recom- mendations of the American Physiological Society [46] and in order to avoid type I errors, alpha value of $p<0.01$ was considered to be significant for all the comparative analyses.

\section{Whole sample analyses}

For the whole sample, demographical data, levels of CSF $\mathrm{A} \beta_{42}, \mathrm{CSF}$ tau, and CSF ptau, and APOE $\varepsilon 4$ frequencies were calculated. Regarding the longitudinal change in both the AFE-T and the standard neuropsychological tests, repeated-measures analyses of variance (ANOVA) were run in order to compare baseline and follow-up performances.

Pearson bivariate correlations were calculated to assess overall associations between the demographic (age, years of education, and cognitive reserve) and biological (AD CSF biomarkers) data and the difference between baseline and follow-up score in the immediate cued recall of the AFE-T (immediate cued recall difference score). The difference between baseline and follow-up in the immediate cued recall difference score was considered to be the best AFE-T outcome measure, as it is the final score of the test (end of the 2nd learning day).

To explore the relationships between the longitudinal memory performance (in both the AFE-T and a standard neuropsychological test) and relevant factors, a linear model was set up. The first analysis included the AFE-T immediate cued recall difference score as the dependent variable and the second one included the FCSRT cued recall difference score. For the second analysis, the FCSRT cued recall difference score was used as a homologous variable of the immediate cued recall difference score of the AFE$\mathrm{T}$ (final cued recall output). Age, the SCD-Q score, CSF $A \beta_{42}$, and CSF tau were included as covariates in both analyses.

\section{Further analyses: differences between CBN-Tau ${ }^{\uparrow}$ and $C B N-T a u^{\downarrow}$}

Demographic data, levels of CSF $\mathrm{A} \beta_{42}, \mathrm{CSF}$ tau, and CSF ptau, and $A P O E \varepsilon 4$ frequencies were compared using $t$-tests for independent samples and $C h i$-square analyses when appropriate. We ran ANOVAs to explore possible cross-sectional differences between CBN-Tau ${ }^{\uparrow}$ and CBN-Tau ${ }^{\downarrow}$ on the AFE-T at the baseline and at the follow-up assessments.

Regarding the longitudinal change, dependent samples $t$-tests were run to compare within-group differences between baseline and follow-up scores of the AFE-T in both CBN-Tau ${ }^{\uparrow}$ and CBN-Tau ${ }^{\downarrow}$. Follow- 
up between-group differences were analyzed using mixed-model ANCOVA controlling for age, years of education, and CSF $A \beta_{42}$ levels with post-hoc Bonferroni corrections.

\section{RESULTS}

\section{Sample characteristics}

Thirty-two cognitively and biologically normal (CBN) subjects were included in the present study. Age ranged between 53 and 78 years, and educational level between 5 and 18 years. Female/male ratio was 62.5/37.5. Regarding the AD CSF biomarker levels, the mean CSF $\mathrm{A} \beta_{42}$ was 824.1 (SD 210.9) $\mathrm{pg} / \mathrm{ml}$ [557.5-1405.0], CSF tau was 228.6 (SD 72.3) pg/ml [83.5-364.2], and CSF ptau was 50.9 (SD 13.5) pg/ml [23.5-71.0]. Only 2 subjects (6.2\%) were APOE $\varepsilon 4$ positive (see Table 1).

\section{Variables associated with longitudinal cognitive decline}

Pearson correlations were run in order to find overall associations between demographic and biological data and cognitive changes. The immediate cued recall difference score (i.e., the difference between the follow up and baseline score on the final cued recall output) was used as an indicator of longitudinal cognitive decline. Demographic data such as age $(r=-0.24 ; p=0.20)$, years of education $(r=0.19$; $p=0.29)$ and cognitive reserve $(r=0.16 ; p=0.41)$ were not associated with the immediate cued recall difference score. Neither did the biological variables of CSF $\mathrm{A} \beta_{42}(r=-0.04 ; p=0.82)$ and CSF ptau $(r=-0.24 ; p=0.18)$. However, we found a significant negative correlation between CSF tau and the immediate cued recall difference score $(r=-0.414$; $p<0.01$; see scatter plot in Fig. 1), indicating worse recall associated to higher CSF tau levels.

\section{CSF tau driving longitudinal memory changes}

The first linear model analysis showed that CSF tau $(B=-0.17 ; p<0.05)$ predicted the performance in the immediate cued recall difference score of the AFET. Age $(B=-0.029 ; p=0.705)$, the SCD-Q score $(B=-0.107 ; p=0.155)$, and CSF $\mathrm{A}_{42}(B=0.002$; $p=0.317)$ did not predict change on this cognitive variable. The second model, with the FCSRT cued recall difference score as the dependent variable, did not reveal any statistically significant predictors [age $(B=-0.089 ; p=0.381)$, SCD-Q score $(B=-0.130$; $p=0.188), \mathrm{CSF} A \beta_{42}(B=-0.003 ; p=0.327)$, and CSF tau $(B=0.014 ; p=0.148)]$.

\section{Performance in the AFE-T}

\section{Validation study}

Thirty healthy younger adults were recruited and randomly divided into two groups (group A, for word list $\mathrm{A}$; and group $\mathrm{B}$, for word list $\mathrm{B}$ ). Age ranged between 17 and 29 years (mean 20.27; $\mathrm{SD}=2.57$ ) and all subjects were college students. There were no significant differences between the validation groups on age or educational level.

Importantly for the present purposes, independent samples t-tests revealed no significant differences between the validation groups A and B in any of the learning runs or in the immediate cued recall (with $p$-values ranging between 0.20 and 0.86 ; see Fig. 2). As expected, when comparing the overall performances in lists A and B between the validation subjects and the study participants, significant differences were found in favor of the younger validation subjects in both list $\mathrm{A}(\mathrm{t}(14)=3.74, p<0.01)$ and list $\mathrm{B}(\mathrm{t}(14)=3.98, p<0.01)$.

\section{The AFE-T in the whole sample}

We compared baseline and 18-month follow-up scores of the AFE-T in the whole sample (Table 2; Fig. 2). ANOVAs showed significant differences with a better performance in the baseline session in comparison with the follow-up in the runs $6(\mathrm{~F}(1$, $31)=7.13 ; p<0.01)$ and $7(\mathrm{~F}(1,31)=18.19 ; p<0.01)$ of the first learning day, and in the runs $1(\mathrm{~F}(1$, $31)=13.09 ; p<0.01), 2(F(1,31)=7.20 ; p<0.01)$, 7 (i.e., total learning score; $\mathrm{F}(1,31)=7.81 ; p<0.01$ ) and immediate cued recall $(\mathrm{F}(1,31)=7.61 ; p<0.01)$.

\section{Standard neuropsychological tests in the whole sample}

Comparisons of baseline and follow-up scores on standard neuropsychological tests are shown in Supplementary Table 1. There was no significant difference in global cognition between baseline and follow-up scores $(\mathrm{F}(1,30)=1.37 ; p=0.25)$, as assessed by the MMSE. Nor was there a significant difference on the verbal intelligence score $(\mathrm{F}(1,30)=4.12 ; p=0.51)$. Most of the scores obtained at the follow-up assessment were higher than at the baseline, even reaching statistical significance for the free recall subtest of the FCSRT $(\mathrm{F}(1,30)=12.25$; $p<0.01)$. 
Table 1

Demographics, biological data, and AD CSF levels of the whole sample

\begin{tabular}{llll}
\hline \multicolumn{2}{c}{ Demographics } & \multicolumn{1}{c}{ Biological data \& AD CSF levels } \\
\hline Female/male ratio & $62.5 / 37.5$ & $A P O E \varepsilon 4$ (\% positive) & $6.2 \%$ \\
Age & $64.6($ SD 6.2) [53-78] & $\mathrm{A} \beta_{42}$ & $824.1 \mathrm{pg} / \mathrm{ml}$ (SD 210.9) \\
Years of education & $11.4(\mathrm{SD} 3.8)[5-18]$ & Tau & $228.6 \mathrm{pg} / \mathrm{ml}$ (SD 72.3) \\
CRQ & $16.6(\mathrm{SD} 4.5)[6-22]$ & ptau & $50.9 \mathrm{pg} / \mathrm{ml}$ (SD 13.5) \\
\hline
\end{tabular}

Data are presented as means (SD; standard deviation) and [range]. CSF, cerebrospinal fluid; $\mathrm{A} \beta_{42}$, amyloid- $\beta$ isoform 42; Tau, total tau; ptau, phosphorylated tau; CRQ, Cognitive Reserve Questionnaire.
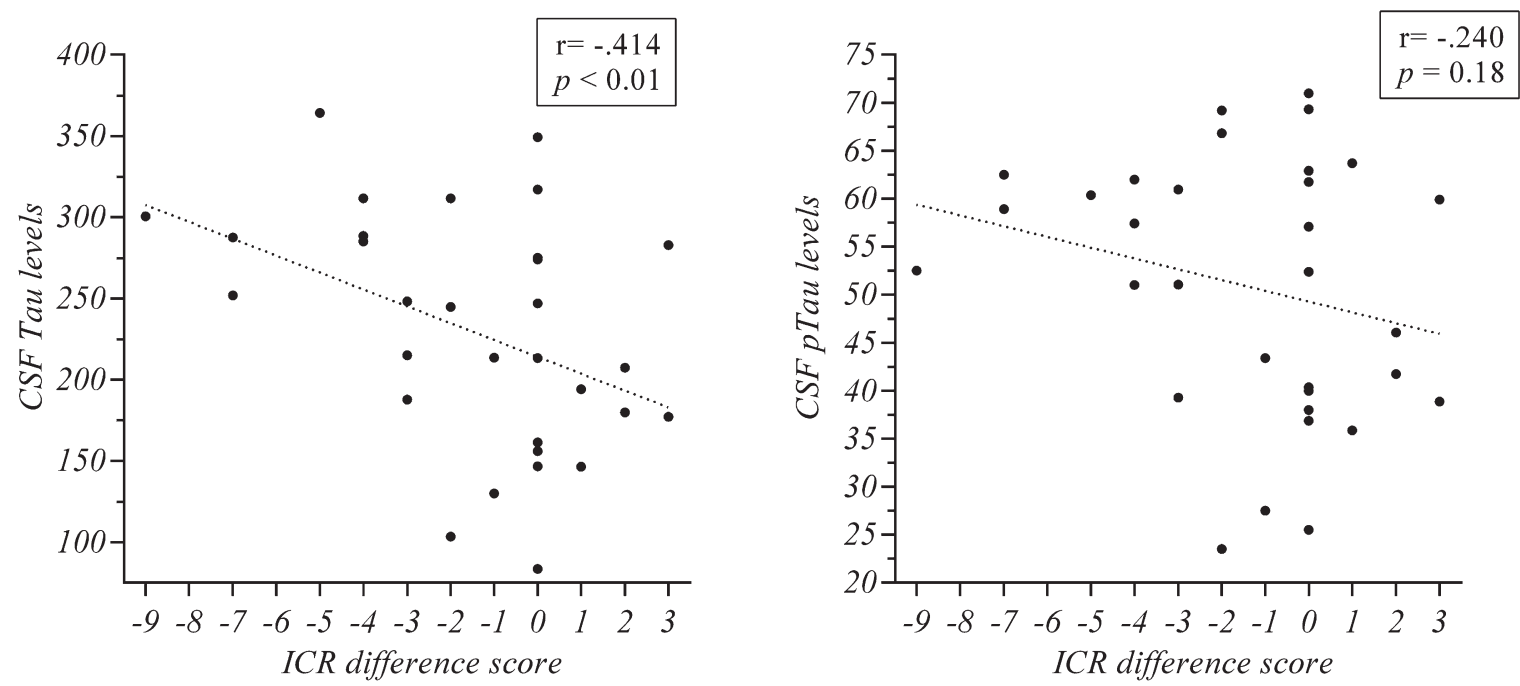

Fig. 1. Correlations in the whole sample between CSF tau and CSF pTau levels and the immediate cued recall difference score of the AFE-T. ICR, immediate cued recall of the AFE-T (difference between baseline and follow-up scores).

First learning day

Second learning day

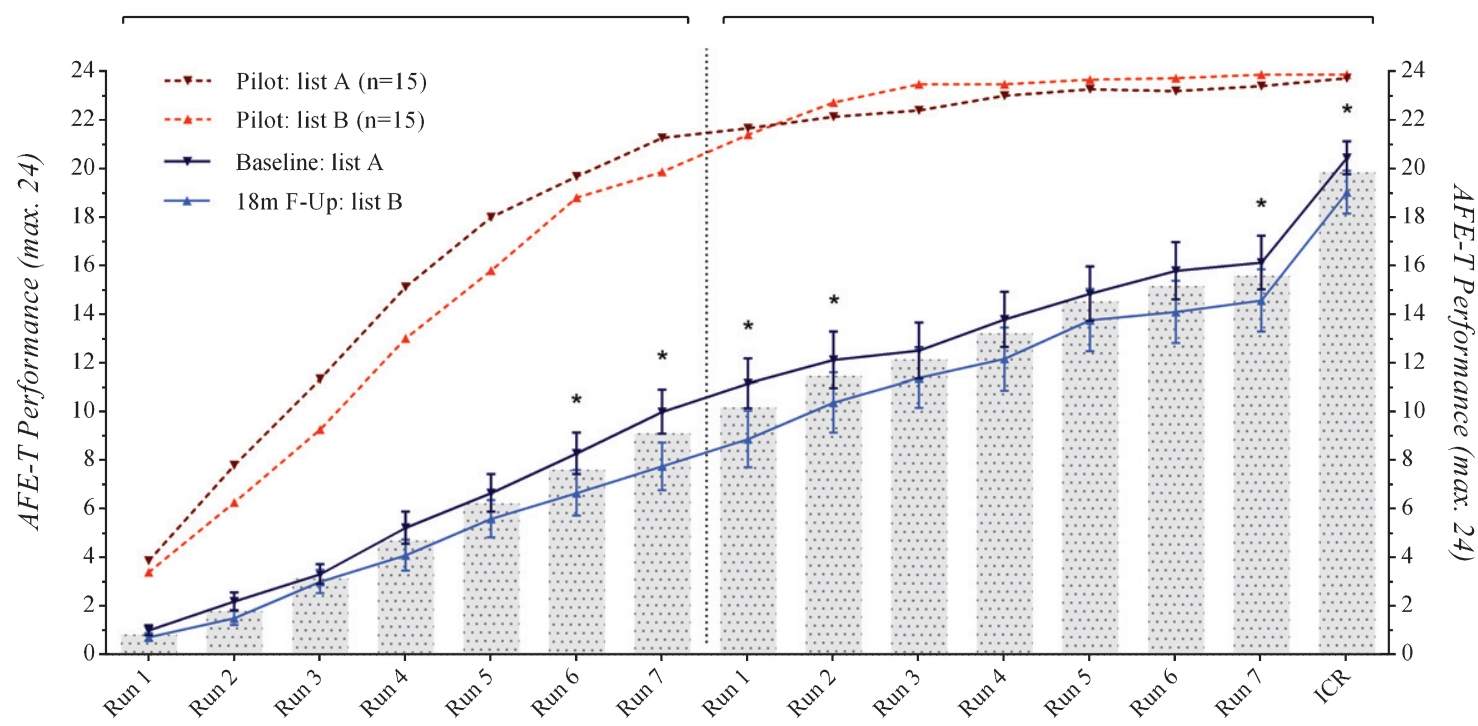

Learning Runs

Fig. 2. AFE-T baseline and follow-up performance in the whole sample. ICR, immediate cued recall, ${ }^{*} p<0.01$. 
Table 2

ANOVA of the AFE-T baseline and follow-up scores in the whole sample

\begin{tabular}{lcccc}
\hline Runs & $\begin{array}{c}\text { List A (N = 32) } \\
\text { Baseline }\end{array}$ & $\begin{array}{c}\text { List B (N = 32) } \\
18 \text { month F-up }\end{array}$ & $F$ & $p$ \\
\hline LS1_R1 & $1.0($ SD 1.2) & 0.7 (SD 0.9) & 1.55 & 0.222 \\
LS1_R2 & 2.2 (SD 2.0) & 1.5 (SD 1.6) & 4.15 & 0.050 \\
LS1_R3 & 3.3 (SD 2.3) & 3.0 (SD 2.7) & 0.35 & 0.557 \\
LS1_R4 & $5.2($ SD 3.7) & 4.1 (SD 3.6) & 4.46 & 0.043 \\
LS1_R5 & 6.6 (SD 4.3) & 5.6 (SD 4.3) & 3.22 & 0.083 \\
LS1_R6 & 8.3 (SD 4.8) & 6.6 (SD 5.3) & 7.13 & $0.009^{*}$ \\
LS1_R7 & 10.0 (SD 5.1) & 7.7 (SD 5.6) & 18.19 & $0.001^{* *}$ \\
LS2_R1 & 11.2 (SD 5.7) & 8.9 (SD 6.5) & 13.09 & $0.001^{* *}$ \\
LS2_R2 & 12.1 (SD 6.5) & 10.4 (SD 6.9) & 7.20 & $0.009^{*}$ \\
LS2_R3 & 12.5 (SD 6.6) & 11.4 (SD 6.9) & 2.70 & 0.111 \\
LS2_R4 & 13.8 (SD 6.4) & 12.1 (SD 7.3) & 5.08 & 0.031 \\
LS2_R5 & 14.8 (SD 6.4) & 13.7 (SD 7.2) & 2.46 & 0.127 \\
LS2_R6 & 15.8 (SD 6.7) & 14.1 (SD 7.2) & 6.46 & 0.016 \\
LS2_R7 & 16.1 (SD 6.3) & 14.5 (SD 7.3) & 7.81 & $0.009^{*}$ \\
ICR & 20.4 (SD 3.8) & 19.0 (SD 4.9) & 7.61 & $0.009^{*}$ \\
\hline
\end{tabular}

Data are presented as means (SD; standard deviation). LS1, 1st learning day; LS2, 2nd learning day; R, learning run number; LS2_R7, total learning score; ICR, immediate cued recall. ${ }^{*} p<0.01 ;{ }^{* *} p<0.005$.

Further analyses: comparisons between CBN-Tau ${ }^{\downarrow}$ and $C B N-T a u^{\uparrow}$ groups

\section{Group characteristics}

Demographic and biological data for both CBN$\mathrm{Tau}^{\downarrow}$ and CBN-Tau${ }^{\uparrow}$ groups are shown in Table 3. No differences between CBN-Tau ${ }^{\downarrow}$ and CBN-Tau ${ }^{\uparrow}$ groups were found in age $(\mathrm{t}(30)=0.80 ; p=0.428)$, years of education $(\mathrm{t}(30)=0.09 ; p=0.928)$, cognitive reserve $(\mathrm{t}(26)=-1.03 ; p=0.312)$, or CSF A $\beta_{42}$ levels $(\mathrm{t}(30)=2.04 ; p=0.039)$. There were no significant differences between groups in terms of gender distribution $\left(\chi^{2}=0.35 ; p=0.554\right)$ or in APOE $\varepsilon 4$ allele frequency $\left(\chi^{2}=1.88 ; p=0.170\right)$. Significant differences were found in CSF tau ( $\mathrm{t}(30)=9.32 ; p<0.01)$ and CSF ptau $(\mathrm{t}(30)=6.31 ; p<0.01)$.

\section{Differences between $C B N-T a u^{\uparrow}$ and CBN-Tau $\downarrow$ groups}

ANOVAs were run to determine whether CBN$\mathrm{Tau}^{\uparrow}$ and CBN-Tau ${ }^{\downarrow}$ groups showed cross-sectional differences at baseline and/or follow-up performance in the AFE-T.

There were no significant differences between groups in either baseline or follow-up performance (with $\mathrm{p}$ values ranging from 0.184 to 0.960 and 0.596 to 0.967 , respectively).

Regarding the longitudinal change within each group, dependent samples t-tests were run in order to examine differences between baseline and followup learning runs. For CBN-Tau ${ }^{\downarrow}$, learning runs 5 and 7 of the first learning day of the follow-up were significantly lower than at the baseline. In the $\mathrm{CBN}-\mathrm{Tau}^{\uparrow}$ group, these differences were found in the runs 6 and 7 (i.e., total learning score) and in the immediate cued recall of the second learning day (Table 4; Fig. 3). When ANCOVAs were run to analyze longitudinal between-group differences, the performance difference between the baseline and follow-up immediate cued recall scores between the $\mathrm{CBN}-\mathrm{Tau}^{\downarrow}$ and $\mathrm{CBN}-\mathrm{Tau}^{\uparrow}$ groups revealed that the $\mathrm{CBN}-\mathrm{Tau}^{\uparrow}$ had a larger difference in the immediate cued recall difference score than the $\mathrm{CBN}-\mathrm{Tau}^{\downarrow}$ subjects $\operatorname{did}(\mathrm{F}(1,31)=8.37 ; p<0.01)$. The differences in the rest of the learning runs showed no significant differences between groups (see Supplementary Table 2; Fig. 3).

\section{Neuroimaging analyses}

We evaluated which regions of grey matter volume predicted the total learning score and immediate cued recall of the AFE-T at baseline, as well as their longitudinal change (total learning score and immediate cued recall difference scores).

\section{Cross-sectional VBM}

At baseline, both total learning score and immediate cued recall showed positive correlations with grey matter volume in a similar network including the left and right posterior cerebellar lobes, right and left medial temporal regions, and the right middle 
Table 3

Demographics, biological data, and AD CSF levels of the CBN-Tau ${ }^{\downarrow}$ and CBN-Tau ${ }^{\uparrow}$ groups

\begin{tabular}{|c|c|c|c|c|}
\hline Parameters & $\mathrm{CBN}-\mathrm{Tau}^{\downarrow}(n=16)$ & ${\mathrm{CBN}-\mathrm{Tau}^{\uparrow}(n=16)}$ & $t$ & $p$ \\
\hline \multicolumn{5}{|l|}{ Demographics } \\
\hline Gender (\% women) & $68.8 \%$ & $56.3 \%$ & $0.35^{\mathrm{a}}$ & 0.554 \\
\hline Age & 63.7 (SD 6.7) [53-78] & 65.5 (SD 5.6) [56-73] & 0.80 & 0.428 \\
\hline Years of education & $11.3(\mathrm{SD} 3.3)[6-18]$ & $11.4(\mathrm{SD} 4.4)[5-18]$ & 0.09 & 0.928 \\
\hline CRQ & 17.7 (SD 4.2) [9-22] & 15.9 (SD 4.8) [6-22] & -1.03 & 0.312 \\
\hline \multicolumn{5}{|l|}{ Biological data \& CSF } \\
\hline APOE $\varepsilon 4$ (\% positive $)$ & $0 \%$ & $12.5 \%$ & $1.88^{\mathrm{a}}$ & 0.170 \\
\hline $\mathrm{A} \beta_{42}$ & $747.7 \mathrm{pg} / \mathrm{ml}(\mathrm{SD} 231.5)$ & $900.5 \mathrm{pg} / \mathrm{ml}(\mathrm{SD} 161.0)$ & 2.04 & 0.039 \\
\hline Tau & $167.3 \mathrm{pg} / \mathrm{ml}(\mathrm{SD} 39.2)$ & $290.0 \mathrm{pg} / \mathrm{ml}(\mathrm{SD} 35.1)$ & 9.32 & $0.001^{*}$ \\
\hline ptau & $40.8 \mathrm{pg} / \mathrm{ml}(\mathrm{SD} 11.1)$ & $60.9 \mathrm{pg} / \mathrm{ml}(\mathrm{SD} 6.1)$ & 6.31 & $0.001^{*}$ \\
\hline
\end{tabular}

Data are presented as means (SD; standard deviation). CSF, cerebrospinal fluid; CBN, cognitively and biologically normal; $A \beta_{42}$, amyloid- $\beta$ isoform 42; Tau, total tau; ptau, phosphorylated tau; $C R Q$, cognitive reserve questionnaire. ${ }^{\mathrm{a}} \chi^{2}$ statistic; ${ }^{*} p<0.01$.

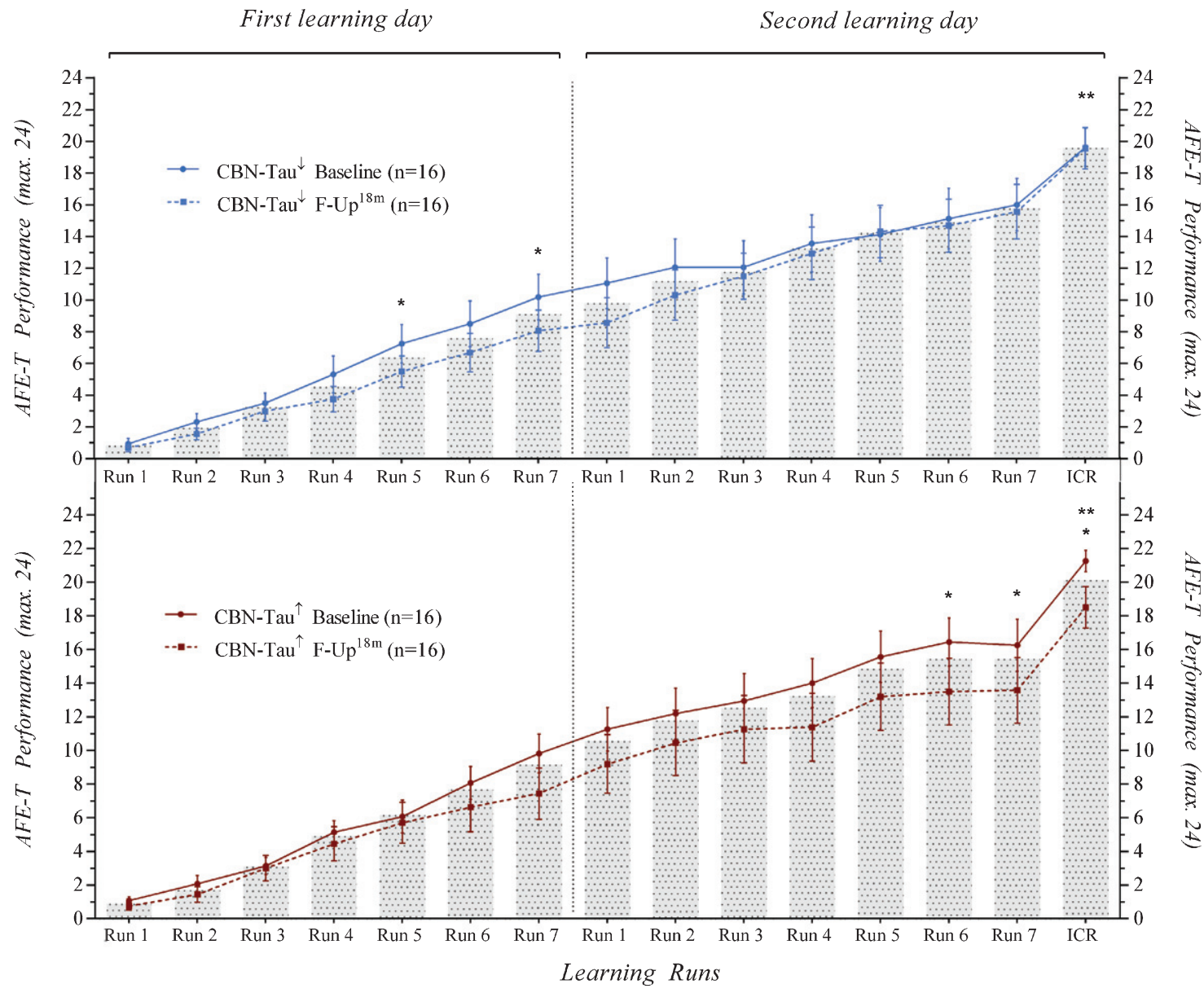

Fig. 3. Comparison of the AFE-T baseline and follow-up performance in the CBN-Tau ${ }^{\downarrow}$ and CBN-Tau ${ }^{\uparrow}$ groups. CBN, cognitively and biologically normal; ICR, immediate cued recall; ${ }^{*} p<0.01$ (within-group differences); ${ }^{* *} p<0.01$ (between-group difference).

occipital gyrus (Fig. 4). For the total learning score, an additional left middle frontal cluster was a significant predictor. No grey matter regions showed a significant negative correlation with either score.

\section{Longitudinal VBM}

The longitudinal decline in both scores correlated with the rate of grey matter volume reduction in the right posterior cerebellar lobe (Fig. 4). Volume 
Table 4

Dependent samples $t$-tests for the AFE-T baseline and follow-up scores of the CBN-Tau ${ }^{\downarrow}$ and CBN-Tau ${ }^{\uparrow}$ groups

\begin{tabular}{|c|c|c|c|c|c|c|c|c|}
\hline \multirow[b]{2}{*}{ Runs } & \multicolumn{4}{|c|}{$\mathrm{CBN}-\mathrm{Tau}^{\downarrow}(n=16)$} & \multicolumn{4}{|c|}{${\mathrm{CBN}-\mathrm{Tau}^{\uparrow}(n=16)}$} \\
\hline & $\begin{array}{c}\text { List A } \\
\text { Baseline }\end{array}$ & $\begin{array}{c}\text { List B } \\
18 \mathrm{~m} \mathrm{F-Up}\end{array}$ & $t$ & $p$ & $\begin{array}{c}\text { List A } \\
\text { Baseline }\end{array}$ & $\begin{array}{c}\text { List B } \\
18 \mathrm{~m} \mathrm{F-Up}\end{array}$ & $t$ & $p$ \\
\hline$\overline{L S 1 \_R 1}$ & 0.9 (SD 1.4) & 0.6 (SD 0.9) & 0.77 & 0.451 & $1.0(\mathrm{SD} 0.9)$ & $0.7(\mathrm{SD} 0.9)$ & 0.96 & 0.352 \\
\hline LS1_R2 & $2.3(\mathrm{SD} 2.1)$ & $1.6(\mathrm{SD} 1.5)$ & 1.96 & 0.068 & $2.0(\mathrm{SD} 2.0)$ & $1.4(\mathrm{SD} 1.8)$ & 1.01 & 0.289 \\
\hline LS1_R3 & $3.5(\mathrm{SD} 2.6)$ & $3.0(\mathrm{SD} 2.4)$ & 0.67 & 0.510 & $3.1(\mathrm{SD} 2.0)$ & $3.0(\mathrm{SD} 3.0)$ & 0.16 & 0.873 \\
\hline LS1_R4 & $5.3(\mathrm{SD} 4.6)$ & $3.7(\mathrm{SD} 3.2)$ & 2.33 & 0.034 & $5.1(\mathrm{SD} 2.7)$ & $4.4(\mathrm{SD} 4.0)$ & 0.82 & 0.423 \\
\hline LS1_R5 & $7.2(\mathrm{SD} 4.8)$ & $5.5(\mathrm{SD} 3.9)$ & 3.36 & $0.004^{*}$ & $6.1(\mathrm{SD} 3.9)$ & $5.7(\mathrm{SD} 4.8)$ & 0.35 & 0.728 \\
\hline LS1_R6 & 8.5 (SD 5.7) & 6.7 (SD 4.8) & 2.83 & 0.013 & 8.1 (SD 3.8) & 6.6 (SD 5.8) & 1.36 & 0.194 \\
\hline LS1_R7 & $10.2(\mathrm{SD} 5.7)$ & $8.1(\mathrm{SD} 5.2)$ & 3.29 & $0.005^{*}$ & $9.8(\mathrm{SD} 4.6)$ & $7.4(\mathrm{SD} 6.1)$ & 2.77 & 0.014 \\
\hline LS2_R1 & 11.1 (SD 6.4) & $8.6(\mathrm{SD} 6.3)$ & 2.64 & 0.018 & $11.3(\mathrm{SD} 5.2)$ & $9.2(\mathrm{SD} 6.9)$ & 2.39 & 0.030 \\
\hline LS2_R2 & $12.0(\mathrm{SD} 7.1)$ & $10.3(\mathrm{SD} 6.3)$ & 2.28 & 0.037 & $12.2(\mathrm{SD} 6.0)$ & $10.4(\mathrm{SD} 7.7)$ & 1.62 & 0.127 \\
\hline LS2_R3 & $12.0(\mathrm{SD} 6.7)$ & $11.5(\mathrm{SD} 5.8)$ & 0.59 & 0.562 & $13.0(\mathrm{SD} 6.5)$ & $11.2(\mathrm{SD} 8.0)$ & 1.69 & 0.112 \\
\hline LS2_R4 & $13.6(\mathrm{SD} 7.2)$ & $12.9(\mathrm{SD} 6.6)$ & 0.62 & 0.543 & $14.0(\mathrm{SD} 5.7)$ & $11.4(\mathrm{SD} 8.0)$ & 2.61 & 0.019 \\
\hline LS2_R5 & $14.1(\mathrm{SD} 6.7)$ & $14.3(\mathrm{SD} 6.6)$ & -0.21 & 0.834 & $15.6(\mathrm{SD} 6.1)$ & $13.2(\mathrm{SD} 8.0)$ & 2.35 & 0.032 \\
\hline LS2_R6 & $15.1(\mathrm{SD} 7.6)$ & $14.7(\mathrm{SD} 6.7)$ & 0.55 & 0.588 & $16.4(\mathrm{SD} 5.7)$ & 13.5 (SD 7.9) & 2.95 & $0.009^{*}$ \\
\hline LS2_R7 & $16.0(\mathrm{SD} 6.6)$ & $15.6(\mathrm{SD} 6.8)$ & 0.79 & 0.437 & $16.2(\mathrm{SD} 6.2)$ & 13.5 (SD 7.8) & 2.96 & $0.009^{*}$ \\
\hline ICR & $19.6(\mathrm{SD} 4.7)$ & $19.6(\mathrm{SD} 5.2)$ & 0.14 & 0.884 & $21.2(\mathrm{SD} 2.5)$ & $18.5(\mathrm{SD} 4.9)$ & 3.40 & $0.004^{*}$ \\
\hline
\end{tabular}

Data are presented as means (SD; standard deviation). CBN, cognitively and biologically normal; LS1, 1st learning day; LS2, 2nd learning day; R, learning run number; LS2_R7, total learning score; ICR, immediate cued recall. ${ }^{*} p<0.01$.

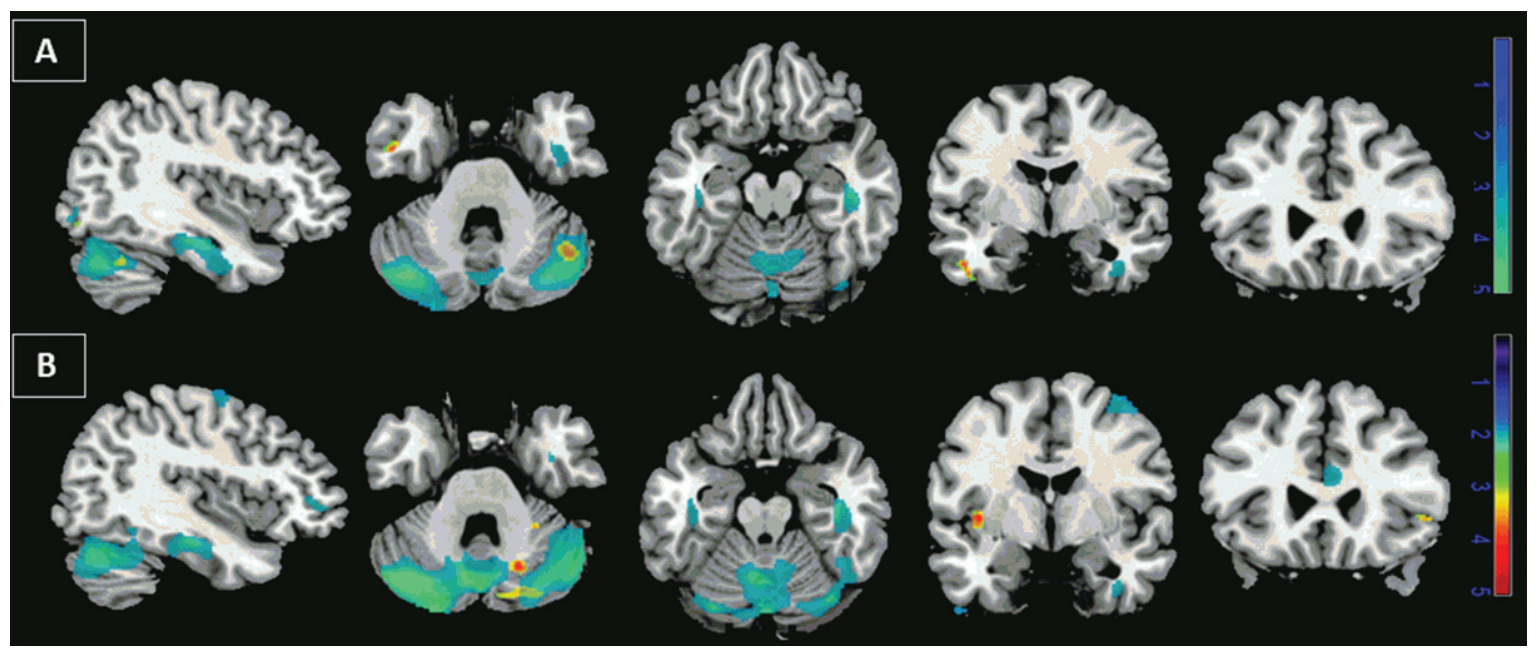

Fig. 4. Grey matter volume correlates of the Immediate Cued Recall (A) and Total Learning Score (B) of the AFE-T. Grey matter volume correlates of the immediate cued recall (A) and total learning score (B) performance on the AFE-T. Green represents cross-sectional performance at baseline. Hot color represents the correlates of longitudinal change. Results are displayed at a $p<0.005$ threshold for visualization purposes.

reduction in additional clusters in the left insula for the total learning score, and the left anterior inferior temporal lobe for the immediate cued recall, correlated with decline in memory performance. All grey matter volume correlates of cross-sectional and longitudinal performance on the AFE-T are shown in Supplementary Table 3.

\section{DISCUSSION}

We conducted the first study examining a specific sample of cognitively healthy subjects with a nor- mal pattern of AD CSF biomarkers using a highly demanding learning and memory test and VBM, with the aim to identify the earliest biological and structural variables related to longitudinal cognitive decline in cognitively and biologically normal aging. Our main finding showed that CSF tau is associated with longitudinal cognitive changes in this population. Furthermore, we found different longitudinal cognitive patterns by dividing our cohort into two subgroups based on their CSF tau levels. The VBM results also suggested that performance on the AFE-T is related to grey matter volume in a medial tempo- 
ral, middle frontal, and posterior cerebellar network at baseline, and that there are strategic brain areas driving the observed longitudinal cognitive changes. Our findings suggest that there are biological and structural markers reflecting normal cognitive aging and highlight the critical impact of tau as a good predictor of the earliest memory decline in healthy subjects with normal AD CSF biomarkers. Taken together, since both CSF tau and anatomic MRI are considered biomarkers of neurodegeneration in the current ATN classification [47], our results point the presence of neurodegeneration as a potential predictor of cognitive change.

In the last few years, the relationships between biomarkers and cognition have been intensively studied [25-29, 48] and some studies have suggested a stronger association between cognition and tau than between cognition and $A \beta[11,13,49]$. According to the literature, $A \beta$ accumulates first in the neocortex and then in subcortical areas [50]. Instead, tau usually concentrates first in the medial temporal areas [51] that are closely related to encoding of new information, learning processes and memory. The main finding of the present study was to find of an association between CSF tau and the longitudinal cognitive decline in the AFE-T in a sample of subjects with normal AD CSF biomarker levels. Some longitudinal studies have found associations between cognition and tau $[12,49]$ in cognitively healthy subjects. Hessen et al. [49] studied 122 subjects with subjective cognitive decline (SCD) and found that a subgroup presenting memory decline during the study period had significantly higher CSF tau levels at baseline. However, it has been suggested that SCD population could have a somewhat higher risk of developing incipient cognitive decline than controls [52]. Furthermore, a study by Glodzik et al. [12] found that elevated $p$-tau 231 levels were related to both decreased memory function and MTL atrophy in a group of normal elderly subjects that experienced longitudinal memory decline. Nevertheless, in this study it is important to note that 1) CSF $p$-tau 231 is a specific marker of neurofibrillary pathology and 2) the group with decreased memory function presented lower levels of the $A \beta_{42} / A \beta_{40}$ ratio indicating a noticeable contribution of amyloid deposition. In the present study, our statistical model showed that SCD (measured by the SCD-Q) and CSF $\mathrm{A} \beta_{42}$ were not associated with the immediate cued recall difference score of the AFE-T, and allowed the identification of a unique contribution of CSF tau into predicting the longitudinal memory decline.
An important issue was to further investigate our main finding regarding the CSF tau impact on the cognitive performance of cognitively healthy subjects. In this regard, we identified distinct patterns of cognitive decline in the AFE-T between the two groups that were established according to their CSF tau levels. Our findings are enhanced by the fact that the study groups showed a marginal difference in the CSF $A \beta_{42}$ levels in favor of the group with higher tau levels. This rejects the possibility that $\mathrm{A} \beta$ was contributing to the observed cognitive differences and, again, argues in favor of a unique effect of CSF tau in the memory function. As seen in Fig. 3, the group with higher tau levels performed worse in more runs of the follow-up assessment when compared with the group exhibiting lower levels of tau. Furthermore, in their last runs, the lower tau group reached their baseline performance level, whereas the group with higher levels of tau remained below their baseline level throughout the whole follow-up testing. These results suggest that subjects with lower tau levels exhibited practice effects in comparison with those with higher tau. Importantly, the lack of learning effects has been recently identified as a cognitive marker of subtle cognitive changes [53], highlighting its importance as a predictive variable of future cognitive decline. In addition, the change between the baseline and the follow-up immediate cued recall showed a significant difference in favor of the lower tau group. Taken together, our results suggest that CSF tau levels could have an impact on the learning and memory functions of cognitively healthy individuals, and that highly demanding memory tests such as AFE-T could detect this pathological process even in this population.

Our VBM results also suggest that AFE-T performance is related to grey matter volume in a medial temporal, middle frontal, and posterior cerebellar network at baseline (cross-sectional VBM, $n=29$ ), and that there are strategic brain areas driving the observed longitudinal cognitive changes (longitudinal VBM, $n=20$ for total learning score and $n=23$ for immediate cued recall). We were able to identify grey matter regions the volume of which predicted performance on the AFE-T at baseline, as well as those in which the longitudinal change in volume predicted the amount of decline in the studied measures. Cross-sectional performance at baseline in both total learning and cued recall measures was associated with grey matter volume in a medial temporal and posterior cerebellar network. For the total learning score, an additional left middle frontal cluster was 
a significant predictor, perhaps reflecting a larger executive function component than that involved in cued recall. These results are in line with extensive previous literature showing that the medial temporal and prefrontal regions are related to performance on a variety of memory tasks [54-56]. The predominant brain region involved in both cross-sectional and longitudinal performance was the posterior cerebellum. This finding was unexpected. However, the role of the posterior cerebellum in a variety of cognitive tasks including language, learning, memory and especially executive functions such as working memory and planning is well established [57-61]. The large extension of the cerebellar clusters with respect to the cortical clusters may be explained by the healthy cognitive and biological state of our cohort. In normal aging, the posterior cerebellar lobes show accelerated volume reduction with respect to other structures [62], and this reduction may be more relevant to cognitive performance than typically shown by studies of diseased patients with cortical lesions. In line with our results, other recent studies including similarly aged and cognitively healthy cohorts [63-65] show involvement of the cerebellum in memory and executive function tests. Taken together, our findings showed structural correlates of cognitive performance in a well-characterized sample of subjects with normal cognition and normal AD CSF biomarker levels, providing evidence on the most vulnerable brain systems related to learning and memory in aging.

Another important topic of the present work concerned the sensitivity of cognitive measures in the assessment of cognitively healthy subjects. Our whole-sample analyses of the standard neuropsychological tests showed improved follow-up performance on most of the tasks, suggesting clear practice effects that are commonly observed in cognitively healthy individuals [53, 66-68]. Practice effects have been explained by several factors such as knowledge about testing procedures, previously learned strategies, and a reduced sense of novelty and nervousness when re-testing [69]. On the other hand, our findings on the AFE-T showed a poorer performance at the follow-up assessment when compared with the baseline, suggesting that the use of a demanding cognitive measure can alleviate practice compound that may mask subtle cognitive changes in cognitively normal subjects. This is crucial for pinpointing age-related cognitive changes that otherwise could become underestimated [70]. Importantly for the present research, our validation study demon- strated that both baseline and follow-up lists of stimuli were equally challenging and therefore comparable, and thus the observed follow-up changes could not be explained by list-related differences. Taken together, our findings support the idea that standard neuropsychological tests are not sensitive enough to detect subtle cognitive changes in a cognitively healthy population $[71,72]$, and suggest that the AFE-T could be a sensitive task for the early detection of longitudinal cognitive decline.

This study has some limitations. One important issue is its small sample size which limits the strength of the statistical analyses. However, the comprehensive AFE-T protocol allowed for a better and more fine-grained characterization of learning and memory processes. With AFE-T, participants' learning and memory functions were evaluated using 15 learning runs at both baseline and follow-up assessments for both free and cued recall. Regarding the AFE$\mathrm{T}$, it is also important to note that only the form A was administered at baseline and form B at the 18month follow-up. Although our pilot study indicated that lists A and B did not differ in terms of level of difficulty, it would have been more appropriate to counterbalance their presentation for the baseline and follow-up. Another potential limitation of the present study concerns the multiple comparisons problem that arises from the large number of statistical comparisons performed. This was dealt with post-hoc Bonferroni corrections, albeit this is an admittedly conservative method. Moreover, following recommendations [46] to avoid type I errors, alpha level was set to $p<0.01$ for all the comparative analyses. Finally, considering the novelty of the present findings and the limited sample size, the results have to be interpreted with caution and replication is called for in further studies involving larger samples of cognitively and biologically normal subjects.

\section{Conclusions}

The present study is the first to show that in a sample of cognitively healthy individuals with normal AD CSF biomarker levels, tau, a marker of neurodegeneration, is associated with longitudinal cognitive decline. Furthermore, our results pinpoint critical brain areas related to cross-sectional and longitudinal learning and memory performance in this well-characterized sample. Taken together, our results suggest the presence of neurodegeneration as a potential predictor of cognitive change in healthy individuals. The present findings shed light on the 
impact of CSF tau in cognition and provide important knowledge about the relationships between biological status and the earliest age-related cognitive changes.

\section{ACKNOWLEDGMENTS}

This work has been supported by the Carlos III Health Institute (project PI14/00563), integrated in the State Plan of Scientific and Technical Research and Innovation (2013-2016), and co-financed by the European Regional Development Fund (ERDF) "Una manera de hacer Europa".

We thank all volunteers for their participation in this study; without their collaboration this work would have not been possible.

Authors' disclosures available online (https://www.j-alz.com/manuscript-disclosures/190046r1).

\section{SUPPLEMENTARY MATERIAL}

The supplementary material is available in the electronic version of this article: http://dx.doi. org/10.3233/JAD-190046.

\section{REFERENCES}

[1] Fjell AM, McEvoy L, Holland D, Dale AM, Walhovd KB (2014) What is normal in normal aging? Effects of aging, amyloid and Alzheimer's disease on the cerebral cortex and the hippocampus. Prog Neurobiol 117, 20-40.

[2] Harada CN, Natelson Love MC, Triebel KL (2013) Normal cognitive aging. Clin Geriatr Med 29, 737-752.

[3] Nyberg L, Maitland SB, Rönnlund M, Bäckman L, Dixon RA, Wahlin $\AA$, Nilsson L-G (2003) Selective adult age differences in an age-invariant multifactor model of declarative memory. Psychol Aging 18, 149-160.

[4] Kawas C, Gray S, Brookmeyer R, Fozard J, Zonderman A (2000) Age-specific incidence rates of Alzheimer's disease: The Baltimore Longitudinal Study of Aging. Neurology 54, 2072-2077.

[5] Stern Y (2009) Cognitive reserve. Neuropsychologia 47, 2015-2028.

[6] Stern Y (2012) Cognitive reserve in ageing and Alzheimer's disease. Lancet Neurol 11, 1006-1012.

[7] Yaffe K, Fiocco AJ, Lindquist K, Vittinghoff E, Simonsick EM, Newman AB, Satterfield S, Rosano C, Rubin SM, Ayonayon HN, Harris TB (2009) Predictors of maintaining cognitive function in older adults. Neurology 72, 2029-2035.

[8] Petersen RC, Doody R, Kurz A, Mohs RC, Morris JC, Rabins P V, Ritchie K, Rossor M, Thal L, Winblad B (2001) Current concepts in mild cognitive impairment. Arch Neurol 58, 1985-1992.

[9] Nyberg L, Lövdén M, Riklund K, Lindenberger U, Bäckman L (2012) Memory aging and brain maintenance. Trends Cogn Sci 16, 292-305.
[10] Dekhtyar M, Papp K V, Buckley R, Jacobs HIL, Schultz AP, Johnson KA, Sperling RA, Rentz DM (2017) Neuroimaging markers associated with maintenance of optimal memory performance in late-life. Neuropsychologia 100, 164-170.

[11] Nelson PT, Alafuzoff I, Bigio EH, Bouras C, Braak H, Cairns NJ, Castellani RJ, Crain BJ, Davies P, Del Tredici K, Duyckaerts C, Frosch MP, Haroutunian V, Hof PR, Hulette CM, Hyman BT, Iwatsubo T, Jellinger KA, Jicha GA, Kövari E, Kukull WA, Leverenz JB, Love S, Mackenzie IR, Mann DM, Masliah E, McKee AC, Montine TJ, Morris JC, Schneider JA, Sonnen JA, Thal DR, Trojanowski JQ, Troncoso JC, Wisniewski T, Woltjer RL, Beach TG (2012) Correlation of Alzheimer disease neuropathologic changes with cognitive status: A review of the literature. $J$ Neuropathol Exp Neurol 71, 362-381.

[12] Glodzik L, de Santi S, Tsui WH, Mosconi L, Zinkowski R, Pirraglia E, Wang HY, Li Y, Rich KE, Zetterberg H, Blennow K, Mehta P, de Leon MJ (2011) Phosphorylated tau 231, memory decline and medial temporal atrophy in normal elders. Neurobiol Aging 32, 2131-2141.

[13] Rolstad S, Berg AI, Bjerke M, Johansson B, Zetterberg H, Wallin A (2013) Cerebrospinal fluid biomarkers mirror rate of cognitive decline. J Alzheimers Dis 34, 949-956.

[14] Rentz DM, Amariglio RE, Becker JA, Frey M, Olson LE, Frishe K, Carmasin J, Maye JE, Johnson KA, Sperling RA (2011) Face-name associative memory performance is related to amyloid burden in normal elderly. Neuropsychologia 49, 2776-2783.

[15] Amariglio RE, Frishe K, Olson LE, Wadsworth LP, Lorius N, Sperling RA, Rentz DM (2012) Validation of the Face Name Associative Memory Exam in cognitively normal older individuals. J Clin Exp Neuropsychol 34, 580-587.

[16] Alegret M, Valero S, Ortega G, Espinosa A, Sanabria A, Hernández I, Rodríguez O, Rosende-Roca M, Mauleón A, Vargas L, Martín E, Ruíz A, Tárraga L, Amariglio RE, Rentz DM, Boada M (2015) Validation of the Spanish version of the Face Name Associative Memory Exam (S-FNAME) in cognitively normal older individuals. Arch Clin Neuropsychol 30, 712-720.

[17] Parra MA, Abrahams S, Logie RH, Méndez LG, Lopera F, Della Sala S (2010) Visual short-term memory binding deficits in familial Alzheimer's disease. Brain 133, 27022713.

[18] Laine M, Salmelin R (2010) Neurocognition of new word learning in the native tongue: Lessons from the ancient farming equipment paradigm. Lang Learn 60, 25-44.

[19] Cornelissen K, Laine M, Renvall K, Saarinen T, Martin N, Salmelin R (2004) Learning new names for new objects: Cortical effects as measured by magnetoencephalography. Brain Lang 89, 617-622.

[20] Hultén A, Laaksonen H, Vihla M, Laine M, Salmelin R (2010) Modulation of brain activity after learning predicts long-term memory for words. J Neurosci 30, 15160-15164.

[21] Grönholm P, Rinne JO, Vorobyev VA, Laine M (2007) Neural correlates of naming newly learned objects in MCI. Neuropsychologia 45, 2355-2368.

[22] Grönholm-Nyman P, Rinne JO, Laine M (2010) Learning and forgetting new names and objects in MCI and $\mathrm{AD}$. Neuropsychologia 48, 1079-1088.

[23] Tuomiranta LM, Càmara E, Froudist Walsh S, Ripollés P, Saunavaara JP, Parkkola R, Martin N, Rodríguez-Fornells A, Laine M (2015) Hidden word learning capacity through orthography in aphasia. Cortex 50, 174-191.

[24] Tort-Merino A, Valech N, Peñaloza C, Grönholm-Nyman P, León M, Olives J, Estanga A, Ecay M, Fortea J, Martínez- 
Lage P, Molinuevo JL, Laine M, Rodríguez-Fornells A, Rami L (2017) Early detection of learning difficulties when confronted with novel information in preclinical Alzheimer's disease stage 1. J Alzheimers Dis 58, 855-870.

[25] Dumurgier J, Hanseeuw BJ, Hatling FB, Judge KA, Schultz AP, Chhatwal JP, Blacker D, Sperling RA, Johnson KA, Hyman BT, Gómez-Isla T (2017) Alzheimer's disease biomarkers and future decline in cognitive normal older adults. J Alzheimers Dis 60, 1451-1459.

[26] Ho JK, Nation DA (2018) Neuropsychological profiles and trajectories in preclinical Alzheimer's disease. J Int Neuropsychol Soc 24, 693-702.

[27] Tijms BM, Vermunt L, Zwan MD, van Harten AC, van der Flier WM, Teunissen CE, Scheltens P, Visser PJ (2018) Preamyloid stage of Alzheimer's disease in cognitively normal individuals. Ann Clin Transl Neurol 5, 1037-1047.

[28] Pettigrew C, Soldan A, Moghekar A, Wang M-C, Gross AL, O'brien R, Albert M (2015) Relationship between cerebrospinal fluid biomarkers of Alzheimer's disease and cognition in cognitively normal older adults. Neuropsychologia 78, 63-72.

[29] Sanabria A, Alegret M, Rodriguez-Gomez O, Valero S, Sotolongo-Grau Ó, Monté-Rubio G, Abdelnour C, Espinosa A, Ortega G, Perez-Cordon A, Gailhajanet A, Hernandez I, Rosende-Roca M, Vargas L, Mauleón A, Sanchez D, Martin E, Rentz DM, Lomeña F, Ruiz A, Tarraga L, Boada M, FACEHBI study group (2018) The Spanish version of Face-Name Associative Memory Exam (S-FNAME) performance is related to amyloid burden in subjective cognitive decline. Sci Rep 8, 3828.

[30] Valech N, Mollica MA, Olives J, Tort A, Fortea J, Lleo A, Belén S-S, Molinuevo JL, Rami L (2015) Informants' perception of subjective cognitive decline helps to discriminate preclinical Alzheimer's Disease from normal aging. $J$ Alzheimers Dis 48, S87-S98.

[31] Grober E, Buschke H (1987) Genuine memory deficits in dementia. Dev Neuropsychol 3, 13-36.

[32] Kaplan E, Goodglass H, Weintraub S (2001) Boston Naming Test, Lea \& Febiger, Philadelphia.

[33] Roth C (2011) Boston Diagnostic Aphasia Examination. Encyclopedia of Clinical Neuropsychology. Pearson Canada Assessment Inc., Canada.

[34] Warrigton E, James M (1991) Visual Object and Space Perception battery (VOSP), Thames Valley Test Co, England.

[35] Reitan R (1985) Neuropsychological Test Battery: Theory and clinical interpretation. Neuropsychology Press, USA.

[36] Stroop J (1935) Studies of interference in serial verbal reactions. J Exp Psychol 28, 643-662.

[37] Smith A (1968) Symbol Digits Modalities Test. Learning Disorders. Western Psychological Services, Los Angeles.

[38] Wechsler D (2008) Wechsler Adult Intelligence Scale (WAIS), Pearson, USA.

[39] Folstein MF, Folstein SE, McHugh PR (1975) "Mini-mental state". A practical method for grading the cognitive state of patients for the clinician. J Psychiatr Res 12, 189-198.

[40] Gomar JJ, Ortiz-Gil J, McKenna PJ, Salvador R, Sans-Sansa B, Sarró S, Guerrero A, Pomarol-Clotet E (2011) Validation of the Word Accentuation Test (TAP) as a means of estimating premorbid IQ in Spanish speakers. Schizophr Res 128, 175-176.

[41] Rami L, Mollica MA, García-Sanchez C, Saldafia J, Sanchez B, Sala I, Valls-Pedret C, Castellvi M, Olives J, Molinuevo JL (2014) The subjective cognitive decline questionnaire (SCD-Q): A validation study. J Alzheimers Dis $\mathbf{4 1}$, 453-466.
[42] Davis CJ, Perea M (2005) BuscaPalabras: A program for deriving orthographic and phonological neighborhood statistics and other psycholinguistic indices in Spanish. Behav Res Methods 37, 665-671.

[43] Ashburner J, Friston KJ (2005) Unified segmentation. Neuroimage 26, 839-851.

[44] Ashburner J (2007) A fast diffeomorphic image registration algorithm. Neuroimage 38, 95-113.

[45] Ashburner J, Ridgway GR (2013) Symmetric diffeomorphic modeling of longitudinal structural MRI. Front Neurosci 6 , 2-19.

[46] Curran-Everett D, Benos DJ (2004) Guidelines for reporting statistics in journals published by the American Physiological Society. Am J Physiol Regul Integr Comp Physiol 287, R247-R249.

[47] Jack CR, Bennett DA, Blennow K, Carrillo MC, Dunn B, Haeberlein SB, Holtzman DM, Jagust W, Jessen F, Karlawish J, Liu E, Molinuevo JL, Montine T, Phelps C, Rankin KP, Rowe CC, Scheltens P, Siemers E, Snyder HM, Sperling R, Elliott C, Masliah E, Ryan L, Silverberg N (2018) NIAAA Research Framework: Toward a biological definition of Alzheimer's disease. Alzheimers Dement 14, 535-562.

[48] Donohue MC, Sperling RA, Petersen R, Chung-Kai S, Weiner MW, Aisen PS (2017) Association between elevated brain amyloid and subsequent cognitive decline among cognitively normal persons. JAMA 317, 2305-2316.

[49] Hessen E, Nordlund A, Stalhammar J, Eckerström M, Bjerke M, Eckerström C, Göthlin M, Fladby T, Reinvang I, Wallin A (2015) T-Tau is associated with objective memory decline over two years in persons seeking help for subjective cognitive decline: A report from the Gothenburg-Oslo MCI study. J Alzheimers Dis 47, 619-628.

[50] Thal DR, Rüb U, Orantes M, Braak H (2002) Phases of A beta-deposition in the human brain and its relevance for the development of AD. Neurology 58, 1791-1800.

[51] Braak H, Braak E (1991) Neuropathological stageing of Alzheimer-related changes. Acta Neuropathol 82, 239-259.

[52] Jessen F, Amariglio RE, van Boxtel M, Breteler M, Ceccaldi M, Chételat G, Dubois B, Dufouil C, Ellis KA, van der Flier WM, Glodzik L, van Harten AC, de Leon MJ, McHugh P, Mielke MM, Molinuevo JL, Mosconi L, Osorio RS, Perrotin A, Petersen RC, Rabin LA, Rami L, Reisberg B, Rentz DM, Sachdev PS, de la Sayette V, Saykin AJ, Scheltens P, Shulman MB, Slavin MJ, Sperling RA, Stewart R, Uspenskaya O, Vellas B, Visser PJ, Wagner M (2014) A conceptual framework for research on subjective cognitive decline in preclinical Alzheimer's disease. Alzheimers Dement 10, 844-852.

[53] Hassenstab J, Ruvolo D, Jasielec M, Xiong C, Grant E, Morris JC (2015) Absence of practice effects in preclinical Alzheimer's disease. Neuropsychology 29, 940-948.

[54] Eyler LT, Sherzai A, Kaup AR, Jeste DV (2011) A review of functional brain imaging correlates of successful cognitive aging. Biol Psychiatry 70, 115-122.

[55] Rugg MD, Vilberg KL (2013) Brain networks underlying episodic memory retrieval. Curr Opin Neurobiol 23, 255260.

[56] Wolk DA, Dickerson BC (2011) Fractionating verbal episodic memory in Alzheimer's disease. Neuroimage 54, 1530-1539.

[57] Guell X, Gabrieli JDE, Schmahmann JD (2018) Triple representation of language, working memory, social and emotion processing in the cerebellum: Convergent evidence from task and seed-based resting-state fMRI analyses in a single large cohort. Neuroimage 172, 437-449. 
[58] Stoodley CJ, Schmahmann JD (2018) Functional topography of the human cerebellum. Handb Clin Neurol 51, 59-70.

[59] Rosenbloom MH, Schmahmann JD, Price BH (2012) The functional neuroanatomy of decision-making. J Neuropsychol Clin Neurosci 24, 266-277.

[60] Kim SG, Uğurbil K, Strick PL (1994) Activation of a cerebellar output nucleus during cognitive processing. Science 265, 949-951.

[61] Desmond JE, Fiez JA (1998) Neuroimaging studies of the cerebellum: Language, learning and memory. Trends Cogn Sci 2, 355-362.

[62] Good CD, Johnsrude IS, Ashburner J, Henson RNA, Friston KJ, Frackowiak RSJ (2001) A voxel-based morphometric study of ageing in 465 normal adult human brains. Neuroimage 14, 21-36.

[63] Cacciaglia R, Molinuevo JL, Sánchez-Benavides G, Falcón C, Gramunt N, Brugulat-Serrat A, Grau O, Gispert JD (2018) Episodic memory and executive functions in cognitively healthy individuals display distinct neuroanatomical correlates which are differentially modulated by aging. Hum Brain Mapp 39, 4565-4579.

[64] Ruscheweyh R, Deppe M, Lohmann H, Wersching H, Korsukewitz C, Duning T, Bluhm S, Stehling C, Keller SS, Knecht S (2013) Executive performance is related to regional gray matter volume in healthy older individuals. Hum Brain Mapp 34, 3333-3346.

[65] Ramanoël S, Hoyau E, Kauffmann L, Renard F, Pichat C, Boudiaf N, Krainik A, Jaillard A, Baciu M (2018) Gray matter volume and cognitive performance during normal aging. A voxel-based morphometry study. Front Aging Neurosci 10, $1-10$.
[66] Machulda MM, Pankratz VS, Christianson TJ, Ivnik RJ, Mielke MM, Roberts RO, Knopman DS, Boeve BF, Petersen RC (2013) Practice effects and longitudinal cognitive change in normal aging vs. incident mild cognitive impairment and dementia in the Mayo Clinic study of aging. Clin Neuropsychol 27, 1247-1264.

[67] Dodge HH, Wang CN, Chang CCH, Ganguli M (2011) Terminal decline and practice effects in older adults without dementia: The MoVIES project. Neurology 77, 722-730.

[68] Jonaitis EM, Koscik RL, La Rue A, Johnson SC, Hermann BP, Sager MA (2015) Aging, Practice effects, and genetic risk in the Wisconsin Registry for Alzheimer's Prevention. Clin Neuropsychol 29, 426-441.

[69] Zehnder AE, Bläsi S, Berres M, Spiegel R, Monsch AU (2007) Lack of practice effects on neuropsychological tests as early cognitive markers of Alzheimer disease? Am J Alzheimers Dis Other Demen 22, 416-426.

[70] Calamia M, Markon K, Tranel D (2012) Scoring higher the second time around: Meta-analyses of practice effects in neuropsychological assessment. Clin Neuropsychol 26, 543-570.

[71] Rentz DM, Parra Rodriguez MA, Amariglio R, Stern Y, Sperling R, Ferris S (2013) Promising developments in neuropsychological approaches for the detection of preclinical Alzheimer's disease: A selective review. Alzheimers Res Ther 5, 58 .

[72] Oh H, Madison C, Haight TJ, Markley C, Jagust WJ (2012) Effects of age and $\beta$-amyloid on cognitive changes in normal elderly people. Neurobiol Aging 33, 2746-2755. 